\title{
El porvenir de las razas: el racialismo en el Perú entre los siglos XIX y XX
}

\author{
Wilber Alejandro Obregón Hilario**
}

Recibido: 5 de abril de 2018 - Aprobado: 20 de junio de 2018

\section{Resumen}

Este artículo tiene por objetivo mostrar la relación entre los discursos científicos y las estrategias de poder que establecieron una jerarquía excluyente en la sociedad peruana a comienzos del siglo XX. Por ende, se examinan las prácticas elaboradas tanto por la oligarquía como por otras formas de poder en el contexto mencionado. El artículo se divide en cuatro partes. Primero se revisarán las principales tesis del racialismo francés, particularmente las investigaciones de Gustave Le Bon y Alfred Fouillée. Segundo, se mostrará la influencia francesa sobre las propuestas racialistas de Javier Prado y Clemente Palma. Tercero, considerando el objetivo propuesto se examinarán las estrategias culturales y políticas que construyeron una identidad del indígena para fines específicos. Finalmente, se plantearán ciertas cuestiones que permitan discutir las posibilidades de ampliar la historia de las ideas hacia una genealogía de las prácticas.

Palabras clave: racialismo, raza, positivismo, indígena, oligarquía.

* Artículo de reflexión. Complemento de la investigación y recopilación de los escritos del filósofo peruano Pedro Zulen, a cargo del grupo de investigación que lleva dicho nombre y del cual formo parte, que fueron publicados luego por la Editorial del Congreso del Perú. Citar como Obregón, W. A. (2019). El porvenir de las razas: el racialismo en el Perú entre los siglos XIX y XX. Análisis, 51(94), 81-100, DOI: https://doi.org/10.15332/10.15332/s0120-8454.2019.0094.04

** Bachiller en Filosofía por la Universidad Nacional Mayor de San Marcos. Miembro del Grupo de Estudios sobre Filosofía Peruana y Latinoamericana Pedro S. Zulen. Lima, Perú. Correo electrónico: janobregolario@gmail.com. Orcid: https://orcid.org/0000-0002-9104-1806 


\title{
The porvenir of the races: The racialism in Peru between the nineteenth and twentieth centuries*
}

\author{
Wilber Alejandro Obregón Hilario**
}

This article aims to show the relationship between scientific discourses and the strategies of power that established an exclusionary hierarchy in Peruvian society at the beginning of the 20th century. Therefore, the practices developed by the oligarchy and other forms of power in the aforementioned context are examined. Likewise, the article is divided into four parts. First, we will review the main theses of French racialism, particularly the investigations of Gustave Le Bon and Alfred Fouillée. Second, the French influence on the racialist proposals of Javier Prado and Clemente Palma will be shown. Third, considering the proposed objective, the cultural and political strategies that built an indigenous identity for specific purposes will be examined. Finally, certain questions will be raised that allow us to discuss the possibilities of expanding the history of ideas towards a genealogy of practices.

Keywords: racism, race, positivism, indigenous, oligarchy.

* Reflection article. Complement of the research and compilation of the writings of the peruvian philosopher Pedro Zulen - by the research group that carries the name and of which I am part- that were later published by the Editorial del Congreso del Perú. Quote as Obregón, W. A. (2019). El porvenir de las razas: el racialismo en el Perú entre los siglos XIX y XX. Análisis, 51(94), 81-100, DOI: https://doi.org/10.15332/10.15332/s0120-8454.2019.0094.04

** Bachelor in Philosophy from the Universidad Nacional de San Marcos. Member of the Grupo de Estudios sobre Filosofía Peruana y Latinoamericana Pedro S. Zulen. Lima, Perú. E-mail: janobregolario@gmail.com. Orcid: https://orcid.org/0000-0002-9104-1806 


\section{L'avenir des races: le "racialisme" au Pérou (XIXe et XXe siécles)*}

Wilber Alejandro Obregón Hilario**

\section{Résumé}

Cet article se propose de montrer la relation existante entre les discours scientifiques et les stratégies de pouvoir ayant établi une hiérarchie d'exclusion au sein de la société péruvienne au début du XXe siècle. De ce fait, on examine les pratiques propres à l'oligarchie ainsi que d'autres formes du pouvoir exercées dans le contexte en question.

Cet articles est divisé en quatre parties : premièrement, on revient sur les thèses du racialisme français, en particulier celles de Gustave Le Bon et Alfred Fouillée. Deuxièmement, on montre l'influence française sur les propositions racialistes de Javier Prado et Clemente Palma. Troisièmement, on analyse les stratégies culturelles et politiques qui ont construit une identité indigène en vue d'obtenir un but précis. Finalement, on pose quelques questions sur les possibilités d'élargir l'histoire des idées afin d'envisager une généalogie des pratiques décrites.

Mots clés: hracialisme, race, positivisme, indigène, oligarchie.

* Article de réflexion écrit dans le cadre d'une recherche sur les textes du philosophe péruvien Pedro Zulen, publiés ultérieurement par les éditions du Congrès, au Pérou. Pour citations: Obregón, W. A. (2019). El porvenir de las razas: el racialismo en el Perú entre los siglos XIX y XX. Análisis, 51(94), 81-100, DOI: https://doi.org/10.15332/10.15332/ s0120-8454.2019.0094.04

** Bachelier en Philosophie l'Universidad Nacional Mayor de San Marcos. Membro du Groupe d'études sur la philosophie péruvienne et latino-américaine Pedro S. Zulen. Lima, Perú. Adresse électronique: janobregolario@gmail.com. Orcid: https://orcid.org/0000-0002-9104-1806. 


\section{Introducción}

A mediados del siglo XIX la mayoría de las colonias americanas había logrado independizarse de las potencias europeas. Sin embargo, los imaginarios y discursos coloniales que abarcan la dimensión cognitiva denominada colonialidad ${ }^{1}$ permanecían intactos. En los países recién independizados estos discursos se objetivaron en diferentes aparatos, como leyes e instituciones que formaron parte de un control político, económico y epistémico. No obstante, la colonialidad también formó subjetividades, modos de vida y pensamiento denominados habitus ${ }^{2}$.

El propósito de esta investigación es examinar los discursos y estrategias ${ }^{3}$ que formaron parte de una distinción étnica frente al otro en el Perú. De esta manera, no solo se verán las investigaciones sobre la raza y el carácter enunciadas por la intelectualidad peruana, sino que también se estudiarán ciertos modos de subjetivación del indígena dentro de la sociedad a inicios del siglo XX. Este procedimiento permitirá sostener la tesis de que si bien existe una influencia europea sobre el discurso racialista peruano, las estrategias de las cuales se valieron los sectores dominantes para gobernar tuvieron una característica propia y específica. Con esto, se concluirá que el discurso racialista ${ }^{4}$ y los procesos de modernización no fueron fenómenos exclusivamente europeos que se difundieron posteriormente a suelo latinoamericano, sino que tuvieron distintos lugares de enunciación dentro del sistema-mundo ${ }^{5}$.

\section{Génesis del racialismo o racismo científico: Fouillée y Le Bon}

Sin duda, Francia ocupa un lugar importante en la difusión de los discursos sobre la raza durante el siglo XIX. El primer objetivo será exponer las principales tesis sobre la raza enunciadas desde el locus intelectual francés para luego demostrar su influencia sobre las investigaciones racialistas en el Perú.

Tal vez el intelectual francés más conocido y criticado fue Arthur Gobineau (18161882). Ya en su célebre Essai sur l'inégalité des races humaine (1853) defiende la tesis de que la mezcla racial conlleva la degeneración de la civilización humana. Es importante agregar que Gobineau distingue entre el aspecto morfológico y el

1 La colonialidad es la dimensión cognitiva de las relaciones coloniales de poder. Tanto la colonialidad como la modernidad son racionalidades que funcionan dentro del sistema-mundo.

2 A partir de Bourdieu (1997), se entiende por habitus el modo en el que los individuos incorporan una serie de valores culturales en relación con su condición de clase.

3 Se entiende por estrategia los diferentes procedimientos del poder para lograr una finalidad establecida.

4 Tanto el racialismo como el racismo dividen al género humano en multiplicidad de razas. Sin embargo, el racialismo no necesariamente propone la superioridad de una raza específica.

5 El sistema-mundo es un modelo que explica las relaciones geoeconómicas y geopolíticas a partir de la colonización de América. 
social de las razas. Por ende, la degeneración no solo es consecuencia de la mezcla de razas o sangre, sino de la misma interacción de las costumbres:

Pienso entonces que la palabra "degenerado", aplicándola a un pueblo, debe significar y significa que este pueblo no tiene el valor intrínseco que anteriormente tenía porque no tiene en sus venas la misma sangre, las alianzas sucesivas han modificado gradualmente su valor. (Gobineau, 1983 [1853], p. 162)

Y agrega que "la corrupción de costumbres, en sí misma la más horrible de las plagas, no juega inevitablemente un papel destructor" (p. 164) por estar en relación con la alternancia de la historia. Entonces, la corrupción puede ser asistida mediante una agenda política. Asimismo, Gobineau establece una concordancia en la estructura jerárquica tanto de la raza como del lenguaje. Ya no se trata de un racismo solo biológico, sino que se toman en cuenta el lenguaje, las costumbres y los conocimientos. Estos aspectos son parte de la reflexión racialista que Gobineau desarrolla.

Por otro lado, también cabe señalar la labor de otros intelectuales cuya influencia abarcó parte de las investigaciones del siglo XX: Hyppolite Taine (1828-1893), Ernest Renan (1823-1892) y Émile Boutmy (1835-1906). No obstante, el autor que estuvo inmerso en el clímax de los debates sobre la raza en relación con la cultura fue Alfred Fouillée (1838-1912). Según el autor de La pensée et les nouvelles écoles anti-intellectualistes, la evolución orgánica y la social están en constante armonía. Asimismo, los saberes tanto científicos como morales están en mutua correspondencia con determinadas formas de identidad social u orgánica. Sin embargo, el principio evolutivo del cual se deriva esta concordancia no lleva necesariamente a la libertad y el progreso. La evolución no presupone estos valores, sino que los produce, al igual que la justicia, la paz y la moral. En cuanto al progreso:

La evolución entre los seres inteligentes y sensibles no puede aparecer como siendo al mismo tiempo un progreso, puesto que el progreso en el fondo no es más que la evolución misma de la inteligencia y de la sensibilidad hacia un máximo que será su estado límite, en otros términos, la variación en el sentido de un engrandecimiento del pensamiento y el bienestar. (Fouillée, 1910, p. 186)

Partir del principio de la evolución como creador de formas de justicia y moral confronta la tesis que sitúa estos ideales en un plano trascendente. Una postura similar la mantiene Jean-Marie Guyau, quien toma como principio a la vida misma. Se trata de un inconsciente colectivo que vendría a reemplazar a todo fundamento divino-trascendente. Esta inmanencia, que Fouillée denomina psicología colectiva (p. 206), influyó en las posteriores investigaciones para determinar el orden jerárquico y evolutivo de cada pueblo del mundo.

Sobre esta temática de las mentalidades colectivas los aportes del médico francés Gustave Le Bon (1841-1931) tuvieron una influencia notable en la élite 
intelectual peruana. El autor de Psicología de las masas (2000), tan referido por Clemente Palma 6 , sostiene que las masas poseen un alma colectiva, invariable y correspondiente a sus características fisiológicas. Se trata del carácter en relación con la raza:

Poco influenciados por la inteligencia, los pueblos están sobre todo guiados por los caracteres de su raza, es decir por un agregado hereditario de sentimientos, deseos, costumbres, tradiciones, aspiraciones que representan los fundamentos esenciales del alma de las naciones. Esta alma nacional da a los pueblos una estabilidad duradera a través de las perpetuas fluctuaciones de las contingencias. $Y$ aquí tocamos con el sustrato invisible de la historia, con las fuerzas secretas que orientan su curso. Es la raza en efecto quien determina la manera en la que los pueblos renacen bajo la influencia de los acontecimientos y los cambios de medio. Dominando las instituciones y los códigos pero también las voluntades de los déspotas, el alma de las razas rige sus destinos. Su conocimiento permite descifrar los jeroglíficos de la historia [...] La raza es la piedra angular sobre la cual reposa el equilibrio de las naciones. (Le Bon, 1912 [1894], p. 2)

Esta cita, extraída de su obra Leyes psicológicas de la evolución de los pueblos ${ }^{7}$, confronta la tesis ilustrada de la igualdad por ser incompatible con el proceso científico: "Hace siglo y medio que los filósofos, ignorando además de la historia primitiva del hombre, las variaciones de su constitución y las leyes de la herencia, lanzaron al mundo la idea de la igualdad de los individuos y de las razas" (pp. 2-3). Le Bon concluye que el género humano presenta diversas especies, cada una descendiente de un tronco particular.

El médico francés muestra una desconfianza por el proceso educativo, que solo puede inculcar inteligencia en una raza inferior hasta cierto punto. Más allá de este el carácter es inherente al género humano. Por tanto, la educación es insuficiente porque no resuelve esta diferencia ontológica:

Sin duda ciertas desigualdades que separan entre sí a los individuos y las razas, son lo bastante poderosas y de visible consistencia para que no se les pueda impugnar con éxito; pero asimismo se cree por lo común que solamente son la consecuencia de diferencias de educación, que todos los hombres nacen igualmente inteligentes y bondadosos y que solo las instituciones les han pervertido. El remedio es muy sencillo: reformar las instituciones y dar a todos los hombres una instrucción idéntica. Así es como las instituciones y la instrucción han venido a ser tenidas como las grandes panaceas por las democracias modernas, como el medio de remediar

6 Clemente Palma (1872-1946) fue un escritor peruano que fundó una narrativa racialista en el Perú a principios del siglo XX. Autor de El porvenir de las razas (1897).

7 Texto base para la tesis de bachillerato de Clemente Palma. 
la desigualdades que tanto pugnan con aquellos inmortales principios, que son las últimas divinidades de nuestro tiempo. (p. 3)

Sin embargo, Le Bon radicaliza las diferencias llevándolas a cuestiones de género e ideología:

La noción quimérica de la igualdad de los hombres, que ha subvertido el mundo, suscitó en Europa una revolución gigantesca, lanzó la América a la sangrienta guerra de secesión y condujo a las colonias francesas a un estado de lamentable decadencia [...] lejos aún de haber entrado en una fase de decadencia, la idea igualitaria continúa predominando en las conciencias. En su nombre, el socialismo, que parece avasallar la mayor parte de los pueblos de Occidente, pretende asegurarles su felicidad; la mujer moderna, olvidando las diferencias mentales profundas que la separan del hombre, reclama los mismos derechos y la misma instrucción que él y acabará, si triunfa, por hacer del europeo un nómada sin hogar y $\sin$ familia. (p. 4)

De esta manera, la educación es deficiente para las razas inferiores y para las mujeres puesto que no altera el carácter inherente. Según el autor de Psicología de las masas, la noción de raza tiene similitudes con la de especie. Si entre humanos y animales nos distinguimos por especies, dentro del mismo género humano existen diversas razas-especies con orígenes distintos. En conclusión, la tesis leboniana sostiene la primacía del carácter sobre los procesos de socialización.

A partir de lo anterior, Le Bon propone una clasificación psicológica de las razas: razas primitivas, representadas por los australianos y los fuéguidos, que viven en un estado de animalidad. A continuación tenemos a las razas inferiores, entre las que se ubican los negros, capaces de rudimentos de civilización, aunque nunca sobrepasaron el estado de barbarie. Luego tenemos a las razas medias, entre las que se encuentran los chinos, mongoles y semitas. Por último, las razas superiores, que se ubican en la cima de la jerarquía establecida y son representadas por los pueblos indoeuropeos, descendientes de las grandes civilizaciones romana y griega.

La jerarquía global que propone el médico francés no solo toma en cuenta la relación carácter-inteligencia. Le Bon cree haber encontrado por qué los acontecimientos de la historia han favorecido a la raza blanca, llevándola a posicionarse sobre los demás pueblos del mundo. En conclusión, el carácter deficitario de la educación mantiene un statu quo ya que las razas inferiores siempre estarán determinadas por su voluntad, su energía y su aptitud inherentes:

Desde el [punto de vista] intelectual la raza no es más que la élite a la cual son debidos los progresos científicos, literarios e intelectuales de una civilización. Desde el punto de vista del carácter, es el promedio social lo que importa conocer para formar exacto concepto de la raza. Del nivel de este promedio es de lo que 
depende el poder de los pueblos. En rigor se puede sobrepasar la intelectualidad de una élite intelectual; pero no se pasa de un determinado nivel de carácter. (p. 49)

Ahora, como complemento científico para su tesis Le Bon recurre a examinar la anatomía de los cráneos humanos ${ }^{8}$. El médico francés establece el volumen del cráneo como criterio de diferenciación intelectual. Efectivamente, encuentra diferencias de tamaño, forma y peso, y a partir de ello recubre de un aura científica las diferencias planteadas. Pero no le basta con lograr una legitimidad científica, sino que ambicionará la legitimidad política a partir de la anterior (aunque sea como proyecto).

La agenda política leboniana, que será retomada luego por Palma, podría leerse en clave biopolítica 9 . Ya hemos visto que tanto Le Bon como Fouillée consideran el cruce de las razas o mestizaje como causa de la degeneración de aquellas. Por lo tanto, el Estado debe plantear ciertas estrategias para gestionar la reproducción de la población, evitar el cruce de las razas y promover su homogeneización:

Los cruzamientos pueden ser un elemento de progreso entre razas superiores muy semejantes, así como los ingleses y los alemanes de América. En cambio, constituyen un elemento de degeneración cuando las razas superiores son muy diferentes. Cruzarse dos pueblos es cambiar al mismo tiempo su constitución física y constitución mental. Los cruzamientos constituyen además el único medio infalible que hay de transformar de una manera fundamental el carácter de un pueblo; solamente la herencia es bastante poderosa para luchar contra la herencia. Solo ella puede formar a la larga una nueva raza con caracteres sicológicos y fisiológicos nuevos. (Le Bon, citado en Quiroz, 2010, p. 49)

Asimismo, podemos detectar un elemento importante en la agenda biopolítica de Le Bon: la eugenesia. Esta intervención sobre la especie humana para promover su mejora es crucial para entender los procesos biopolíticos que se dieron posteriormente en países latinoamericanos. La presente investigación no profundizará en ello ya que tiene como único propósito establecer una linealidad entre las investigaciones de la intelectualidad francesa y la peruana.

Para concluir, mostremos cuáles son las proposiciones principales del racialismo o racismo científico:

a) Solo los pueblos superiores pueden ser los líderes de las historia del género humano.

8 Véase Le Bon (1879), memoria premiada por la Academia de Ciencias y la Sociedad de Antropología de Francia.

9 La biopolítica es una tecnología de poder que se caracteriza por gobernar sobre la población y la especie, de tal manera que pueda administrar aspectos como la higiene, la salud, la natalidad y la reproducción. La presente investigación intenta una lectura biopolítica de la eugenesia en tanto intervención sobre la especie humana. 
b) El mestizaje solo es permitido en tanto sea el cruce de razas superiores; de lo contrario, se dirige a la degeneración de estas.

c) La educación es insuficiente para homogeneizar el carácter psicológico de las razas puesto que este es inherente a cada una.

d) El carácter psicológico de las razas constituye una forma determinada de pueblo y costumbres.

\section{El racialismo en el locus intelectual peruano}

A finales del siglo XIX el Perú atravesaba una etapa de reconstrucción nacional ${ }^{10}$ debido a las consecuencias desastrosas de la guerra con Chile. Se constituía la República Aristocrática (1899-1919), iniciada por el segundo gobierno de Nicolás de Piérola ${ }^{11}$, y aunque existía una relativa calma el país no estaba exento de tensiones de índole política y social. Esta investigación no examinará las consecuencias sociopolíticas de la posguerra, sino ciertos discursos racialistas que surgieron en la intelectualidad peruana a comienzos del siglo XX. De esta manera, se mostrará la influencia de las tesis lebonianas sobre algunos intelectuales peruanos.

El positivismo peruano (1885-1915) - que coexistía con diversas posturas filosóficas, como el naturalismo, el materialismo, el espiritualismo, el neokantismo y el krausismo - tuvo el concepto de raza como un tema de debate. Mediante la recepción de las teorías de Gobineau (1816-1882), Renan (1823-1892), Taine (1828-1882) y Le Bon (1841-1931) el punto de vista racialista más que ser un hecho científico se convirtió en un instrumento de dominación instaurándose como parte de un constructo sociocultural enunciado por la oligarquía civilista durante la República Aristocrática. Pese a que la mayoría de los positivistas peruanos defendían la idea de que las fuerzas de la naturaleza son constituyentes de la especie humana, no todos estaban a favor de la superioridad de una raza frente a otras. Es importante tener en cuenta este punto porque nos da a entender que el positivismo no se reduce al discurso racialista. Asimismo, para las diversas vertientes del pensamiento la educación fue una preocupación constante. Destaca, por ejemplo, la labor realizada por la Asociación Pro-Indígena ${ }^{12}$ en el ámbito tanto educativo como político. No obstante, el escritor Clemente Palma (1872-1946), a diferencia de sus contemporáneos positivistas y demás,

10 En esta etapa de reconstrucción no solo se reconfiguraron los cimientos de nuestra economía; también surgieron debates en torno a lo nacional, el progreso, la educación y el orden jerárquico de nuestra sociedad. En el mundo académico peruano las nuevas sendas del pensamiento no hubiesen sido posibles sin la gestión de la Universidad San Marcos, a cargo del rector Toribio Rodríguez de Mendoza de 1785 a 1815. Cabe destacar la tarea de reformular e implementar ideas científico-filosóficas, así como la de hacer frente al elitismo que prevalecía por cuenta de la anterior gestión jesuita. Es así como, al refundarse la Universidad San Marcos en 1867, surgen nuevas vertientes que acompañan al positivismo dominante de la época.

11 Presidente del Perú entre 1879 y 1881, y luego entre 1895 y 1899.

12 La Asociación Pro-Indígena fue fundada por el filósofo peruano Pedro Zulen. Se ocupó de velar por las necesidades y demandas de los indígenas en las provincias del Perú. 
consideraba imposible la inserción indígena mediante este metódico proceso educativo. El porvenir de las razas en el Perú, su obra capital, estuvo dedicada a dos de sus maestros: Pablo Patrón (1854-1910) y Javier Prado ${ }^{13}$ (1871-1921). A continuación se examina la posición de Prado debido a que presenta similitudes con la tesis leboniana.

En el pensamiento de Prado podemos encontrar el tópico naturalista, tesis que sostiene que las fuerzas de la naturaleza constituyen la esencia del ser humano ${ }^{14}$. Este discurso ya era manejado en la Universidad San Marcos por los representantes de la segunda escolástica. No obstante, se reconfiguró para inicios del siglo XX acercándose a la sociología positivista y el cientificismo. El estado social del Perú durante la dominación española (1894), disertación de Prado para el inicio de clases en la Universidad San Marcos, fue fundamental para el posterior pensamiento de Palma. Sin embargo, el discípulo no recurre a los principios climáticos para entender los procesos históricos del Perú. A inicios del siglo XX esta tesis del clima era refutada cada vez más por las corrientes decimonónicas de la época.

El maestro de Palma, recogiendo lo que ya Hipólito Unanue (1940[1806]) sostenía en su estudio sobre el clima y el carácter peruano, declara que

la temperatura general del Perú, por su posición geográfica, es la de los países meridionales, y bajo la influencia inmediata del sol, la raza es física y moralmente débil [...]. De aquí ser la pereza un vicio inherente a los habitantes de estos climas. El cuerpo enervado desea el reposo y los placeres. La pubertad es precoz así como el desarrollo intelectual; la sensibilidad es exagerada, y las pasiones son violentas, pero pasajeras. La imaginación se desarrolla fogosa y rica; pero vive de ensueños, de teorías, de alucinaciones y de prejuicios. El carácter es suave, indolente, expansivo y sumiso; en sus resoluciones los individuos no son firmes ni consecuentes; se pasa de un extremo al otro; los hombres son retrógrados o radicales, héroes o muy cobardes, con frecuencia ambas cosas. (Prado, 1897 [1894], p. 104)

Vemos cómo Prado aún se apoya en la tesis de la influencia del clima sobre el carácter de los hombres. Sin embargo, lo que su discípulo recoge es la noción de raza desarrollada por su maestro. Este, de manera similar a Le Bon, esquematiza a las razas tradicionales del Perú de la siguiente manera: los blancos, los indios y los negros. Ahora, entre estas hubo un determinado número de combinaciones y agregados: mestizos, zambos, mulatos y chinos. Lo interesante es la relación que establece Prado entre las razas y los males de la sociedad peruana: cada una de aquellas posee un determinado número de males particulares, aunque

13 Pablo Patrón fue un destacado médico peruano y Javier Prado fue un filósofo positivista que llegó a ocupar el cargo de rector de la Universidad Nacional Mayor de San Marcos.

14 Este tópico o discurso ya se puede detectar en el periodo de la segunda escolástica. El naturalismo fue un discurso que no solo justificó la Conquista y la evangelización de los indios, sino que, naturalizó las identidades que se constituían dentro de la Colonia y que traían consigo un orden social jerárquico. Para mayor información, véase Ballón (2011). 
se considera como mal común la corrupción. Ninguna de las razas está exenta de este.

Prado, lector de Le Bon, considera a los blancos como la raza dominante. Los criollos para ser más precisos, fueron decisivos para la Independencia del Perú, del cual ahora son sus gobernantes. Las demás razas si bien no tuvieron un papel importante en el progreso del país, lograron formar lazos de parentesco con individuos de la alta sociedad. Prado señala cómo los negros "tomaron revancha" mezclando su sangre con la de los blancos:

Resumiendo, los negros, considerados como mercancía comercial e importados a América como máquinas humanas de trabajo, debían regar la tierra con el sudor de su frente; pero sin fecundarla, sin dejar sus frutos provechosos. Es la liquidación constante, siempre igual, que hace la civilización en la historia de los pueblos: el esclavo es improductivo en el trabajo, como lo fue en el Imperio romano, como lo ha sido en el Perú; y es en el organismo social un cáncer que va corrompiendo los sentimientos y los ideales nacionales. De esta suerte ha desaparecido el esclavo en el Perú, sin dejar los campos cultivados; y después de haberse vengado de la raza blanca mezclando su sangre con la de esta y rebajando en ese contubernio el criterio moral e intelectual de los que fueron al principio sus crueles amos y más tarde sus padrinos, sus compañeros y sus hermanos. (Prado, 1897 [1894], pp. 125-126)

El criterio moral de la época consideraba lo sensual como signo de maldad e inmoralidad. Asimismo, la sociedad católica mantenía una profunda discreción respecto a lo sexual y los pecados sensuales. Prado parece repetir el tópico de lo sensual: caracteriza a los negros como lujuriosos, lascivos, carentes de toda moralidad.

Respecto a los indios, el maestro sanmarquino reconoce su forma de vivir colectivista. Sin embargo, este ethos se vio amenazado con la Conquista, lo que trajo como consecuencia que el carácter del indio se volviera más sumiso y melancólico:

El indio se concentró y se volvió aún más callado, más reservado, más indiferente, más perezoso y profundamente hipócrita y servil. [...] ¿Para qué enfurecerse contra lo inexistente, si el indio, tímido, débil y miedoso, tenía la conciencia de que no podía luchar contra sus opresores? ¿Para qué trabajar, si su trabajo, por más constante, por más fructífero, jamás lo iba a aprovechar él, sino que debía ir a aumentar la riqueza y la avaricia de sus señores? ¿Cómo no ser hipócrita y servil, cómo no había de ocultar el indio su odio profundo, irreconciliable hacia los blancos; y cómo no había de arrastrarse a sus plantas, con aire humilde, con la sonrisa del esclavo, si a lo único que podía aspirar era a que el español y sus hijos criollos suavizaran en algo su martirio [...]? (p. 126) 
Un aspecto que se rescata en la obra del célebre maestro sanmarquino es que la problemática de la exclusión tenía su raíz en el factor colonial. Es decir, Prado considera que la imposición violenta de parte de los españoles trajo como consecuencia la fragmentación del cuerpo social, la subordinación de distintas razas y la imposibilidad para emprender un proyecto de nación peruana. Por ende, condena el Virreinato y aplaude el gobierno republicano. No obstante, la perspectiva de Prado es similar a la de varios intelectuales del siglo XIX que defendían la independencia de la nación frente al poder peninsular, pero establecían por otra parte una sujeción de las demás clases sociales a la élite criolla.

El maestro sanmarquino también sostiene que el carácter de los peruanos es un aspecto importante para el progreso de la nación. Tal vez por ello no se dedica tanto al ámbito pedagógico, sino que se limita a validar un gobierno republicano ${ }^{15}$ que reproduce el imaginario colonial de lo racial. Según Prado, la sociedad peruana debe tener representantes que sean patrióticos, laboriosos y conscientes de sus deberes políticos y sociales. Sin embargo, este ideal conlleva un plan de control de las poblaciones, de inmigración, de evitar el cruce de las razas. El filósofo peruano condena el mestizaje y se muestra a favor de la inmigración europea; sin embargo, curiosamente en el siglo XX el porcentaje de inmigrantes que arribaron al Perú fue mínimo. La gran mayoría de inmigraciones ocurrió luego de la Independencia y a mitad del siglo XIX. De esta manera, no podemos decir que Prado tuviera un papel protagónico en el impulso de la inmigración europea al Perú. No obstante, su propuesta puede ser leída, al igual que la de Le Bon, en clave de un discurso biopolítico que resonaba a inicios del siglo XX:

Es preciso modificar esta (la raza), renovar nuestra sangre y nuestra herencia por el cruzamiento con otras razas que proporcionen nuevos elementos y substancias benéficas. [...] Es preciso aumentar el número de nuestra población y, lo que es más, cambiar su condición, en sentido ventajoso a la causa del progreso. En América gobernar es poblar, y la población debe buscarse en la inmigración espontánea, atraída por la acción de las leyes, del gobierno y de los particulares, de razas superiores, fuertes, vigorosas, que, al cruzarse con la nuestra traigan ideas prácticas de libertad, de trabajo y de industria. No fomentemos, opongámonos a la inmigración de razas inferiores, que pueden satisfacer intereses particulares, intereses de momento; pero que sacrifican los intereses generales, el porvenir de la patria. La segunda condición es elevar el carácter moral, es educar, antes que todo, antes que construir. (Prado, 1897 [1894], p. 189; énfasis añadidos)

Años después, la obra de Clemente Palma, a quien consideramos uno de los mayores exponentes del racismo en la narrativa peruana, también se enunció desde un locus académico centralista y canónico. Palma se empeñó en promover el racismo a través de la literatura. En El porvenir de las razas, al igual que sus predecesores, Palma propone un proyecto eugenésico:

15 Prado ejerció varios cargos políticos, como canciller, ministro y presidente del Consejo de Ministros del Perú. 
Baste decir que, a semejanza de lo que sucede con los animales, es necesario, para mejorar una raza, fusionarla con una raza superior, en condiciones tales que esta no pueda ser absorbida por aquella; que no haya un antagonismo profundo entre ellas, porque entonces no resulta la combinación sino el hibridismo, un hibridismo que traduce los defectos de ambos componentes; que la irrupción de la raza superior bien sea paulatina, bien sea violenta, se haga en el momento histórico más conveniente; que la ingerencia de la sangre sana sea continua; que siga operando sobre las primeras generaciones de mestizos y que el medio donde se desarrollan sea constante. (Palma, 2007 [1897], p. 144)

Se puede concluir que el racialismo fue enunciado por las élites intelectuales de la capital; asimismo, tuvo defensores en diversas disciplinas. Por ejemplo, en 1920 el médico Felipe Chueca realizó una investigación sobre la capacidad intelectual de los niños y llegó a la conclusión de que la raza blanca ofrecía un índice más elevado. Asimismo, el médico Hermilio Valdizán concordaba con la degeneración de la raza indígena debido a su carácter, y junto a la jurista Susana Lozano concluían que los pueblos indígenas estaban en estado de peligrosidad debido a su constitución. Pese a que estos intelectuales no necesariamente pensaron de una manera racista, sus investigaciones fueron elementos que se acoplaron a todo un dispositivo racial a principios del siglo XX.

Es concluyente que el racismo se difundió por medio de la sociología positivista, la literatura y otros saberes. No obstante, como consecuencia de la guerra con Chile y la necesidad de pensar el Perú como una nación unida se formaron una serie de debates en torno a la figura del indio. Posiblemente una de las razones para ello derivó de que dicha identidad traía consigo una herencia que había sido saboteada, así como una historia de sufrimiento y opresión. Otras de las razones también pueden tener que ver con que los indios conformaban la mayor parte de la población peruana.

Ahora, la respuesta contra la influencia positivista vinculada al racialismo surge con los movimientos denominados indigenismo ${ }^{16}$ e indianismo. Ambos plantearon sus propuestas a través del realismo literario y el arte de las provincias del Perú. Por ende, el indio ya no era solo una persona que arrastraba un pasado lleno de impotencia y sufrimientos, sino que se volvió primero un significante dentro de las confrontaciones simbólicas de la cultura y posteriormente el sujeto político que influiría en grandes movimientos como el Partido Aprista Peruano (PAP) y el Partido Comunista Peruano (PCP).

De lo anterior se extrae la conclusión de que la identidad del indio y la clasificación de la raza fueron temas que se debatieron a nivel académico-cultural y tuvieron sus respectivos antecedentes. Sin embargo, siguiendo a Foucault (2012),

16 El indigenismo fue un movimiento político y cultural que surgió en diversos países de América Latina. En el Perú se relacionó con otras corrientes como el realismo y el indianismo. Entre sus representantes más notables están José María Arguedas, Manuel Scorza, Luis Eduardo Valcárcel Vizcarra, Ciro Alegría, Enrique López Albújar, Gamaliel Churata y Eleodoro Vargas Vicuña. 
el saber siempre está en relación con el poder. Esto significa que los saberes deben ser considerados junto a las diferentes estrategias mediante las cuales un dispositivo ${ }^{17}$ cumple con una finalidad establecida. Independientemente de lo que pensaban estos intelectuales, el racismo formó parte de un imaginario cultural con relación al poder. A continuación, esta investigación mostrará que no se trata solo de un saber académico, sino de la construcción de toda una representación hegemónica en la que todos los individuos se reconocen.

\section{Estrategias racistas y antirracistas}

Como complemento del estudio de las ideas sobre el racialismo y la identidad indígena se realizará un breve examen de las estrategias elaboradas por los sectores dominantes para conservar un statu quo en las relaciones de poder. Esta exploración no solo se ocupa de los mecanismos oligárquicos, sino que veremos tanto una forma de poder que busca aplazar la gubernamentalidad del Estado como la labor de una asociación a favor de las demandas indígenas.

\section{El imaginario de la blancura}

A principios del siglo XX paradójicamente la oligarquía peruana se propuso construir una nación más unida e impulsar la modernización del país. No obstante, si bien se promulgaba la integración de las demás razas, el indio seguía estando ligado a un saber despectivo y a diferentes políticas del gobierno. A la par de estas investigaciones que ya hemos examinado, el sector oligárquico ejecutó una serie de estrategias para conservar el imaginario de la blancura ${ }^{18}$. Tenemos, por ejemplo, la endogamia heredada de la época colonial, que en los siglos XVII y XVIII permitía que la élite criolla mantuviera el capital de la blancura al no mezclarse con otras razas y conservar su estatus dominante. Sin embargo, con la modernización del país a inicios del siglo XX esta estrategia se reconfiguró y tuvo otra finalidad. Por ende, los matrimonios no solo procuraban reforzar la limpieza de sangre (Castro-Gómez, 2005), sino que permitieron que las élites limeñas se sintieran modernas. Vivir en la modernidad del siglo XX llevo a establecer un habitus propio del individuo moderno: vestirse a la moda de París, asistir a clubes exclusivos, aparecer en revistas y páginas sociales. En conclusión, se trató de la Belle Époque limeña.

Mientras el conocimiento académico construía una identidad subordinada del indio y demás razas distintas a la blanca, las estrategias de la élite formaban parte de un pathos que promovía la desigualdad y la desintegración nacional.

17 Se entiende por dispositivo una integración entre saber y poder que actúa mediante ciertas estrategias y discursos definidos de acuerdo a un fin particular.

18 La blancura (Castro-Gómez, 2005) hace referencia al capital simbólico heredado por las élites criollas del siglo XVII y $\mathrm{XVIII}$. Este tipo de capital funcionaba como un imaginario en el que la élite dominante se reconocía como superior a los demás sectores sociales 
La situación del indio se vio particularmente afectada por un sistema de poder denominado gamonalismo. La presente investigación se servirá del análisis realizado por Foucault sobre el poder soberano ${ }^{19}$. En clave foucaultiana podrá entenderse la relación gamonal-campesino a partir de la premisa: hacer morir, dejar vivir.

\section{El gamonalismo}

El gamonalismo fue un sistema de poder heredado de la Colonia y encabezado por la figura del gamonal $^{20}$, término que hace referencia a los dueños de un fundo o hacienda. Es un sistema que descentraliza el poder en favor de una "soberanía" terrateniente y local. Es interesante la doble dinámica que el poder gamonal tenía en relación con la oligarquía limeña. En primer lugar, los mistis servían al Estado para controlar a los indígenas, cuyo mayor porcentaje de población vivía en las provincias. Es válido afirmar que sin la función de los gamonales el gobierno central peruano hubiese sido insuficiente. Sin embargo, el poder gamonal no era homogéneo; es decir, no era posible integrar todas sus relaciones en solo un sistema. Asimismo, los gamonales constantemente se enfrentaban entre sí por los latifundios, que eran los lugares donde se ejercía efectivamente el poder gamonal. Este tipo de poder descentrado y similar al feudalismo europeo fue una amenaza para la gubernamentalidad estatal, que desconocía sus límites: la mayoría de los gamonales buscaba terminar con la centralidad de la oligarquía limeña y promover el federalismo. Ahora bien, ¿cómo era la relación entre el gamonal y el indio?

Los mistis, en su mayoría mestizos, se declaraban profundamente católicos y promovían el racismo mediante su figura paternalista ${ }^{21}$. El indio miraba al gamonal como un protector que a veces lo recompensaba con la bebida, el permiso de desenfreno y las costumbres en común. Sin embargo, la autoridad paterna cometía diversos abusos contra la población indígena, como violaciones, maltratos físicos y marcas con hierros (Flores Galindo, 2001, pp. 104-105). El racismo que caracterizaba esta relación no se vinculaba tanto al fenotipo de la raza: el gamonal también se reconocía en el imaginario de la blancura, aunque no compartía el habitus de la élite limeña. No obstante, el misti construía una realidad en la que se reconocía como superior al indio, con quien establecía las relaciones ambivalentes mencionadas anteriormente.

Como complemento podemos considerar brevemente el debate sobre el sistema gamonal. Durante el gobierno de Augusto B. Leguía ${ }^{22}$, Manuel Vicente

\footnotetext{
19 El gamonal se servía del trabajo indígena, que muchas veces era mal remunerado. Esta racionalidad de la extracción es similar al poder de soberanía (Foucault, 2005).

20 Los gamonales también se hacían denominar mistis. Fueron blancos, mestizos y también indios.

21 Michel Foucault (2005) menciona que una de las relaciones de soberanía más conocidas es la familiar. Este tipo de relaciones se caracterizan por ser asimétricas (por ejemplo, la relación padre-hijo). En nuestro caso, el gamonal, gracias a su poder "soberano", extrae la fuerza de trabajo del indio campesino y a la par le ofrece ciertos beneficios.

22 Presidente del Perú. Su segundo mandato se conoce como el Oncenio (1919-1930).
} 
Villarán ${ }^{23}$ (1873-1958) afirmaba que estas comunidades eran los únicos lugares donde los indios tenían protección. La posición se defendía por ciertos aspectos compartidos por el gamonal y el campesino indígena: hablar quechua y tener costumbres ancestrales andinas. No obstante, Francisco Tudela y Varela ${ }^{24}$ (18761962) criticaba la forma "desmesurada" en la que vivían tanto el indio como el gamonal. En estas comunidades, según Tudela y Varela, solo se propagaban los excesos como el alcoholismo y la lujuria. La conclusión que extrae la presente investigación es que el racismo y el paternalismo estuvieron presentes en esta relación ambivalente.

\section{La Asociación Pro-Indígena (API) y Pedro S. Zulen}

El racismo no fue unánime en el Perú de comienzos del siglo XX. Por tanto, este complemento finalizará mostrando el proyecto antirracista de la API. Como lo mencionamos anteriormente, el indigenismo construyó una identidad del indio que posteriormente influyó en los partidos políticos fundados por Víctor Raúl Haya de la Torre ${ }^{25}$ (1895-1979) y José Carlos Mariátegui ${ }^{26}$ (1894-1930). No obstante, la asociación fundada por Pedro Zulen ${ }^{27}$ (1889-1925) venía trabajando mucho antes de que Mariátegui tomara cartas en el asunto, lo cual puede entenderse como un primer motivo para que se examine la API. El segundo motivo tiene que ver con las muchas demandas que Zulen recoge de los indios y que luego publica en diarios como La Crónica. Así, la siguiente exposición pretende complementar el estudio de las ideas sobre el racialismo con una lectura filosófica de ciertas estrategias políticas que crearon modos de subjetivación antirracista.

El indio no solo fue un significante a nivel de los saberes, sino que formó parte de una estrategia política contra la oligarquía civilista. Ahora, ¿cómo se organizó la API con la finalidad de emancipar a la población indígena? Veamos los puntos propuestos por la API y publicados en el diario El Comercio en 1912:

a) Organización e implantación de escuelas nocturnas o dominicales y ambulantes, para adultos, especialmente destinadas a hacer conocer a los indígenas sus derechos y sus deberes, como hombres de trabajo, como ciudadanos y como elementos sociales; y los medios de defensa que deben emplear para oponerse a los abusos de que son víctimas.

b) Campaña de propaganda y acción eficaz contra todas las fiestas que tiendan a fomentar el alcoholismo y otros vicios entre los

\footnotetext{
23 Jurista y político peruano. Uno de los iniciadores del positivismo en el Perú.

24 Político, abogado y diplomático peruano. Fue un connotado militante del civilismo que se opuso al gobierno de Augusto B. Leguía.

25 Pensador y político peruano, fundador de la Alianza Popular Revolucionaria Americana (Apra) y líder histórico del PAP.

26 Periodista y político peruano, fundador del PCP. Entre sus escritos se destaca Siete ensayos de interpretación de la realidad peruana.

27 Filósofo peruano y uno de los fundadores de la API, de la que fue secretario general desde 1905 hasta 1911.
} 
indígenas, y a hacerlos esclavos de torpes preocupaciones y objeto de servidumbres en los pueblos, y a comprometerse en gastos superiores a los recursos de que puedan normalmente disponer.

c) Circulación y propaganda de las leyes y disposiciones vigentes favorables a los indígenas; estudio de proyectos tendentes a ese objeto; y campaña eficaz contra las leyes y los proyectos destinados a desmejorar o dañar la condición indígena.

d) Estudios y propaganda sobre todo cuanto tienda a fomentar la raza y darle mayor influencia en la vida nacional.

e) Defensa de los indígenas contra los abusos de que sean víctimas por parte de las autoridades políticas, administrativas, civiles y militares; apersonándose ante ellas y amparándolos en sus demandas, en los casos que hubiere lugar.

f) Perseguir especialmente ante las autoridades militares la sanción más eficaz por los abusos que se cometen so pretexto del cumplimiento de las leyes militares sobre conscripción, licenciamiento, etc.

g) Perseguir especialmente ante el poder judicial al amparo de la propiedad indígena, que continuamente es arrebatada por gamonales y propietarios vecinos. (Quiroz, Rojas y Quintanilla, 2015, pp. 328-329)

Los puntos mencionados anteriormente forman parte de la estrategia empleada por la API para respaldar y defender a los indios de las diferentes provincias. Zulen fue descrito como paternalista y socialista por el propio Mariátegui; no obstante, el primero reconoce la figura del indígena ${ }^{28}$ como sujeto histórico y señala que solo una revolución por parte de estas mayorías acabaría con la centralidad oligárquica.

Es así como la API pretende concientizar al indio mediante una propuesta educativa diferente a la sociedad disciplinaria que existía en Lima. A principios del siglo XX la mayoría de los colegios limeños eran católicos, y según Zulen, la enseñanza se caracterizaba por ser dogmática y memorística. Por otro lado, desde fines del siglo XIX, un grupo de adventistas se asentaron en Puno y crearon centros educativos donde se enseñaba a los indígenas a leer la Biblia. No obstante, a diferencia de los colegios católicos de Lima, los adventistas hicieron saber a los indios acerca de los derechos que debían exigir y cómo lograr salir

28 Mariátegui, a diferencia de Zulen, cree que el reformador social será el movimiento proletario. El movimiento indígena se diferencia de aquel porque surge desde las provincias. 
de la ignorancia. De esta manera, se estableció un modelo educativo alternativo encabezado por estos adventistas y la $\mathrm{API}^{29}$.

Sin embargo, la lucha de la API no solo estaba en las provincias. Su labor debía complementarse con la defensa del indígena en los debates frente al sector intelectual elitista de la capital. La temática más importante, que formó parte del problema nacional del indio, fue la educación. Zulen no fue el único que encabezó la defensa, sino que destacaron otros intelectuales como Manuel González Prada (1844-1918), Joaquín Capelo (1852-1925) y Dora Mayer (1868-1959).

La preocupación de Zulen por reivindicar la situación y especialmente la educación del indio lo enfrentaron a las propuestas elitistas de Alejandro Deústua (1849-1945) y a la perspectiva contra los indígenas que sostenía Carlos Enrique Paz Soldán (1885-1972) — este último fue influenciado por el discurso racialista de Clemente Palma - . Zulen responde a Paz Soldán y lo refuta apoyándose en dos autores: el francés Jean Finot y el naturalista danés Herman Jacob Friedrich Kohlbrugge. El último, según Zulen, demostró con contundentes pruebas que el volumen del cráneo no es un factor determinante de la inteligencia. De esta manera, Zulen termina por señalar las deficiencias de la antropología y la psicología de la época, plagadas de prejuicios raciales.

\section{Conclusiones}

Esta investigación examinó los discursos enunciados en el locus intelectual peruano y evidenció la influencia de las tesis del racionalismo francés. Sin embargo, se amplió este examen mostrando las estrategias usadas tanto por la aristocracia como por el gamonalismo y su entrada en conflicto con las resistencias proindígenas. De esta manera, se concluye que el saber discursivo no existe en sí mismo, sino en permanentes relaciones con el poder. Este posibilita la emergencia de ciertos saberes y viceversa.

A partir de ello, surge la necesidad metodológica de entender los procesos históricos de subjetivación sin suponer que las identidades mismas son universales. Es decir, esta investigación afirma que las prácticas son anteriores a cualquiera de sus objetivaciones. Las identidades mismas son efectos de ciertas prácticas históricas y a la vez son campos de intervención de diversas fuerzas en conflicto. Como bien señala Foucault, el error de algunos historiadores es naturalizar ciertas objetivaciones de las prácticas y considerarlas como universales, como si la historia fuera una herramienta que permitiera descubrir la verdadera naturaleza de estos referentes. 
El método que nos podría permitir una ampliación de la historia de las ideas es la genealogía ${ }^{30}$. A partir de ella se podrá: 1) analizar los acontecimientos y las condiciones de posibilidad que permitieron, en un momento histórico dado, construir una ciencia positiva que problematiza y clasifica ciertas objetivaciones (negros, indios, chinos) que son efectos de dichas prácticas (¿Cómo fue posible la emergencia de un saber que se reactualiza con las investigaciones sobre la raza y construye no solo identidades subordinadas sino un locus privilegiado que produce efectos de verdad?); 2) ver la funcionalidad de las prácticas (¿Cómo funcionó ese discurso racialista dentro de las estrategias de poder que permitieron la consolidación de la aristocracia peruana? ¿Cómo estas estrategias permitieron que los indígenas se reconocieran en un modus vivendi y aceptaran ser gobernados por otros?). Estas cuestiones surgen desde la perspectiva genealógica que Nietzsche y Foucault trabajaron en su momento y que actualmente es una herramienta usada para ampliar la historia de las ideas ${ }^{31}$.

Pese a que esta investigación se limita a mostrar la relación saber-poder entre los discursos y tácticas racistas, plantea las interrogantes mencionadas anteriormente como una primera aproximación hacia futuras discusiones dentro del campo de la historia y la filosofía como diagnóstico de nuestro tiempo.

\section{Referencias}

Ballón, J. C. (2011). La complicada historia del pensamiento filosófico peruano: siglos XVII y XVIII (2 tomos). Lima: Fondo Editorial de la UNMSM.

Bourdieu, P. (1997). Razones prácticas. Sobre la teoría de la acción. Barcelona: Editorial Anagrama.

Castro-Gómez, S. (2005). La hybris del punto cero. Ciencia, raza e ilustración en la Nueva Granada (1750-1816). Bogotá: Pontificia Universidad Javeriana.

Foucault, M. (2005). El poder psiquiátrico. Curso en el Collège de France (1973-1974). Buenos Aires: FCE.

Foucault, M. (2012). Vigilar y castigar. Nacimiento de la prisión. Madrid: Biblioteca Nueva.

Fouillée, A. (1910). La science sociale contemporaine. París: Hachette.

30 Esta investigación no es la primera es proponer esta ruta metodológica. Podríamos remontarnos desde las investigaciones del propio Michel Foucault hacia los trabajos de Peter Sloterdijk, Giorgio Agamben, Edward Said, entre otros.

31 Existen diversos filósofos e historiadores en América Latina que han usado de la genealogía para examinar las prácticas que posibilitaron ciertas identidades y modos de vida. Destaca la labor del filósofo Santiago Castro-Gómez, a quien hemos citado en las anteriores páginas. 
Gobineau, A. (1983 [1853]). Essai sur l'inégalité des races humaines. En A. Gobineau. CEuvres I (pp. 148-162). París: Bibliothèque de la Pléiade.

Le Bon, G. (1912 [1894]). Leyes psicológicas de la evolución de los pueblos. Madrid: Daniel Jorro Editor.

Le Bon, G. (2000). Psicología de las masas. Madrid: Moratta.

Mariátegui, J. (2005). Siete ensayos de interpretación de la realidad peruana. Lima: El Comercio.

Palma, C. (2007 [1897]). El porvenir de las razas en el Perú. Solar. Revista de Filosofía Iberoamericana, 3. 137-168.

Prado, J. (1897 [1894]). El estado social del Perú durante la dominación española (Anales Universitarios, tomo XXII). Lima: Imprenta Liberal.

Quiroz, R. (2010). La razón racial. Clemente Palma y el racismo a fines del siglo XIX. Lima: Universidad Científica del Sur.

Quiroz, R., Rojas, J. y Quintanilla, P. (comps.) (2015). Pedro S. Zulen. Escritos reunidos. Lima: Fondo Editorial del Congreso del Perú.

Unanue, H. (1940[1806]). Observaciones sobre el clima de Lima y sus influencias en los seres organizados. Lima: Comisión Nacional Peruana de Cooperación Intelectual. 